\title{
Gynostemium morphology and floral biology of Thottea duchartrei Sivar., A.Babu \& Balach. (Aristolochiaceae), an endemic species from Western Ghats, India
}

\author{
Sayoojia K.S. ${ }^{1,2}$, Sreekala A.K. ${ }^{3} \&$ Shaiju P.N. ${ }^{1^{*}}$ \\ ${ }^{1}$ Post Graduate and Research Department of Botany, Fatima Mata National College, Kollam 691 001, Kerala, India \\ ${ }^{2}$ Research Scholar, University of Kerala, Thiruvananthapuram, Kerala, India \\ ${ }^{3}$ Division of Conservation Biology, Jawaharlal Nehru Tropical Botanic Garden and Research Institute, Palode, Thiruvananthapuram 695562 , \\ Kerala, India \\ *Email: shaiju@fmnc.ac.in
}

\section{ARTICLE HISTORY}

Received: 11 June 2021

Accepted: 14 September 2021

Available online: 01 October 2021

\section{KEYWORDS}

Endemic species

Gynostemium

Morphology

Staminode

Thottea duchartrei

Western Ghats

\section{ABSTRACT}

Gynostemium is a putative floral structure formed by the fusion of the male and female reproductive parts (stamens and carpels) through a process during its development called synorganization. Most of the Indian species of Thottea Rottb. have a prominent gynostemium in their floral architecture, with varying degrees of adnation and complexity. Even though the gynostemium is a significant taxonomic marker for the inter-specific systematics in Thottea, the scepticism and arguments on deciphering its morphology and functional parameters, including the existence of staminodes, makes it imperative to be examined in detail. The present study is the first attempt in this line which aims to explore the morphological characters of gynostemium and reproductive biology of Thottea duchartrei Sivar., A.Babu and Balach., an endemic species in the Western Ghats. Stereo zoom microscopy, SEM and reproductive biological studies were conducted providing special emphasis to the gynostemium. Detailed analysis revealed the structural and functional diversity of gynostemium with regard to its components. The study also helped to recognize the columnar outgrowths on the gynostemium as staminodes. In total, the present study helps to solve the confusions regarding the functional identity of the gynostemium T. duchartrei with regard to its morphology.

\section{Introduction}

Gynostemium is a distinct reproductive structure among angiosperms, which is formed by the fusion of male and female reproductive parts of a flower through a developmental process called synorganization. Synorganization of floral organs can lead to the generation of convergences in immensely distant related clades (1). Ontogenetic studies have pointed out that gynostemium is formed by the congenital fusion of stamens and stigmas $(2,3)$. It is found in plant families such as Aristolochiaceae (2), Orchidaceae (4) and Stylidiaceae (5).

Thottea Rottb. is a medicinal under-shrub belonging to the family Aristolochiaceae, represented by about 45 species throughout the world, distributed across Asia (6). In India, the genus is represented by 14 species, of which ten (T. duchartrei, T. idukkiana, $T$. ponmudiana, $T$. sivarajanii, $T$. adichilthottiana, $T$. dalzellii, T. abrahamii, T. barberi, T. dinghoui and T. sasidharaniana) are endemic to the Peninsular India, three (T. celebica, T. paucifida and T. tomentosa) are endemic to the Andaman and Nicobar islands and one ( $T$. siliquosa) is distributed in the peninsular India and Sri Lanka (7-11). A large number of taxonomically significant studies were conducted on different species of Thottea in India. Extensive studies were carried out on the morphology of trichomes, inflorescence morphology, floral morphology, pollen morphology, chromosome number etc. of different Indian Thottea species (7, 11-14).

Morphological studies helps in defining and classifying different taxa and their relations (15). Studies on micro morphological characters (micro morphology of stem, leaves, flowers, nectaries, pollen grains, seeds etc.) of plants are taxonomically significant as they are helpful in species identification and comparison between different taxa (16-20). The morphological features of perianth and gynostemium have been used extensively for taxonomic characterisation within the family Aristolochiaceae (3, $7,12,13)$. The extent of floral morphological variations is apparently significant within Thottea and the

(C) Sayoojia et al (2021). This is an open-access article distributed under the terms of the Creative Commons Attribution License, which permits unrestricted use, distribution and reproduction in any medium, provided the original author and source are credited (https://creativecommons.org/licenses/by/4.0/). 
variations and flexibilities in terms of the gynostemium seem to be most significant and taxonomically interesting (7). Hence, extensive studies have to be conducted on gynostemium morphology of different species of Thottea at micro-level.

In Thottea, the development of gynostemium is partial in nature and is formed by the fusion of the upper portion of gynoecium and the stamens, in which the gynoecium is divided into a number of lobes on its upper portion (7). With regard to the general floral architecture, the gynostemium in Thottea has a central cylindrical axis, which actually serves as the floral axis, from the base of which three bundles of stamens with three stamens in each of the bundles arise. The terminal portion of the gynostemium is divided into a number of stylar lobes, whose actual functional status in terms of the stigma is yet to be identified. Botanists have different perceptions on the morphology of stylar lobes in Thottea - some consider these structures as stylar lobes (7); some others treat them as stigmatic lobes (7, 21) and still others consider them as structures for capturing pollen grains but not actually belonging to the gynoecium (22). In the present study, the micro morphological and reproductive biological characters of gynostemium in T. duchartrei were explored in detail with an objective to assess its functional parameters in relation to its morphology.

\section{Materials and Methods}

\section{Field studies}

Field studies were confined to two accessions of Thottea duchartrei Sivar., A.Babu and Balach. (Fig. 1A, Accession no. 1, Voucher no. TBGT 95927, GPS coordinates: $9.25^{\circ} \mathrm{N}$ \& $76.88^{\circ} \mathrm{E}$; Pathanamthitta district, Kerala; Accession no. 2, Voucher no. TBGT 95929, GPS coordinates: $9.36^{\circ} \mathrm{N}$ \& $76.41^{\circ} \mathrm{E}$, Kottayam district, Kerala).

\section{Micro morphological studies}

The floral details were analyzed morphologically by stereo zoom microscopy (LEICA EZ4 HD, Switzerland) and SEM. The floral parts for SEM studies were taken from mature opened flowers during mid day. Mature flowers were collected and fixed in FAA. Samples were dehydrated through successive aqueous ethanol solutions of increasing concentration (50-100\%). Finally, the samples were air dried, mounted on metallic stubs and coated with a gold film in a sputter chamber. Samples were observed with a scanning electron microscope (ZEISS EVO 18 Research microscope, Germany).

\section{Pollen viability, in vitro pollen germination and pollen fertility studies}

Pollen viability was analyzed based on Fluorescein Diacetate (FDA) test (23). The observations were made using a trinocular fluorescent research microscope (Nikon Eclipse Ci epifluorescence microscope, Japan). In vitro pollen germination test was conducted using Brewbaker and Kwack's medium (24) supplemented with varying concentrations of sucrose (0.03-50\%). Pollen fertility was checked at different time intervals by acetocarmine staining method (25).

\section{Studies on stigma receptivity}

The stigma receptivity was checked by peroxidase activity test (26). The receptive area on the gynostemium was identified by the cytochemical localization of stigma-surface esterases (27). Stigma receptivity was checked by in vivo pollen germination technique also (28). The pollinated pistils were fixed in Carnoy's fluid for 24 hrs and stored in $70 \%$ ethanol. Later, the pistils were softened with $4 \mathrm{~N} \mathrm{NaOH}$, rinsed and mounted in 1:1 mixture of Aniline blue and 10\% glycerine (29). The preparations were analyzed using trinocular fluorescent research microscope (ZEISS Axio Observer.A1, Germany).

\section{Results}

\section{Morphology of gynostemium}

The gynostemium of Thottea duchartrei is only partial in terms of the fusion of its reproductive parts (Fig. 1B). It was seen as a partial fusion product of basal portion of the style and filaments of the stamens. There were three bundles of stamens and each bundle

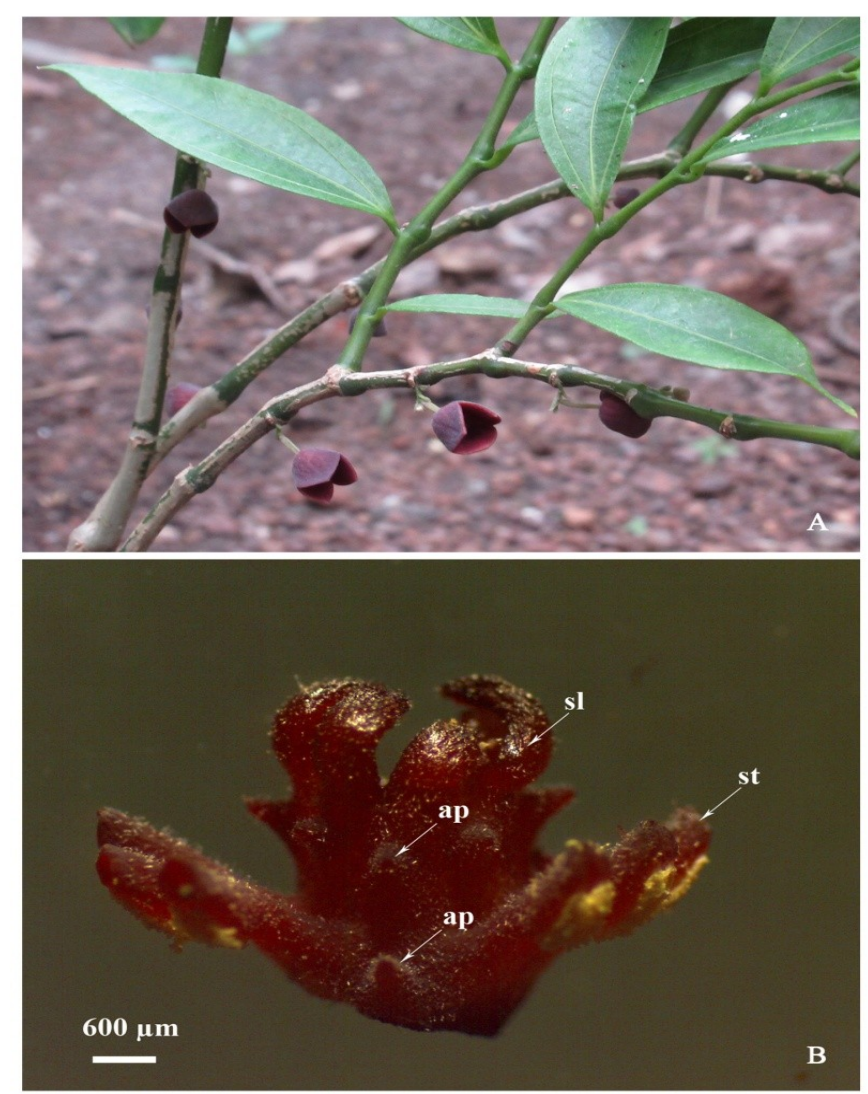

Fig. 1. Habit and morphology of gynostemium in T. duchartrei. (A) Habit with flowers; (B) Gynostemium (stylar lobes closed-non receptive stage); sl: stylar lobe, st: stamen, ap: appendage.

consisted of three extrorse stamens $(3+3+3)$. But, flowers with $2+2+3,3+3+4,3+3+5,3+4+4$ were also seen. Rarely, 4+4 stamen pattern was seen in flowers with bilobed perianth (Fig. 2A). Very rarely, 5 bundles of stamens were seen in flowers with five perianth lobes (Fig. 2B). The filaments of stamens were darker when compared to the remaining parts of gynostemium, and were densely covered with 


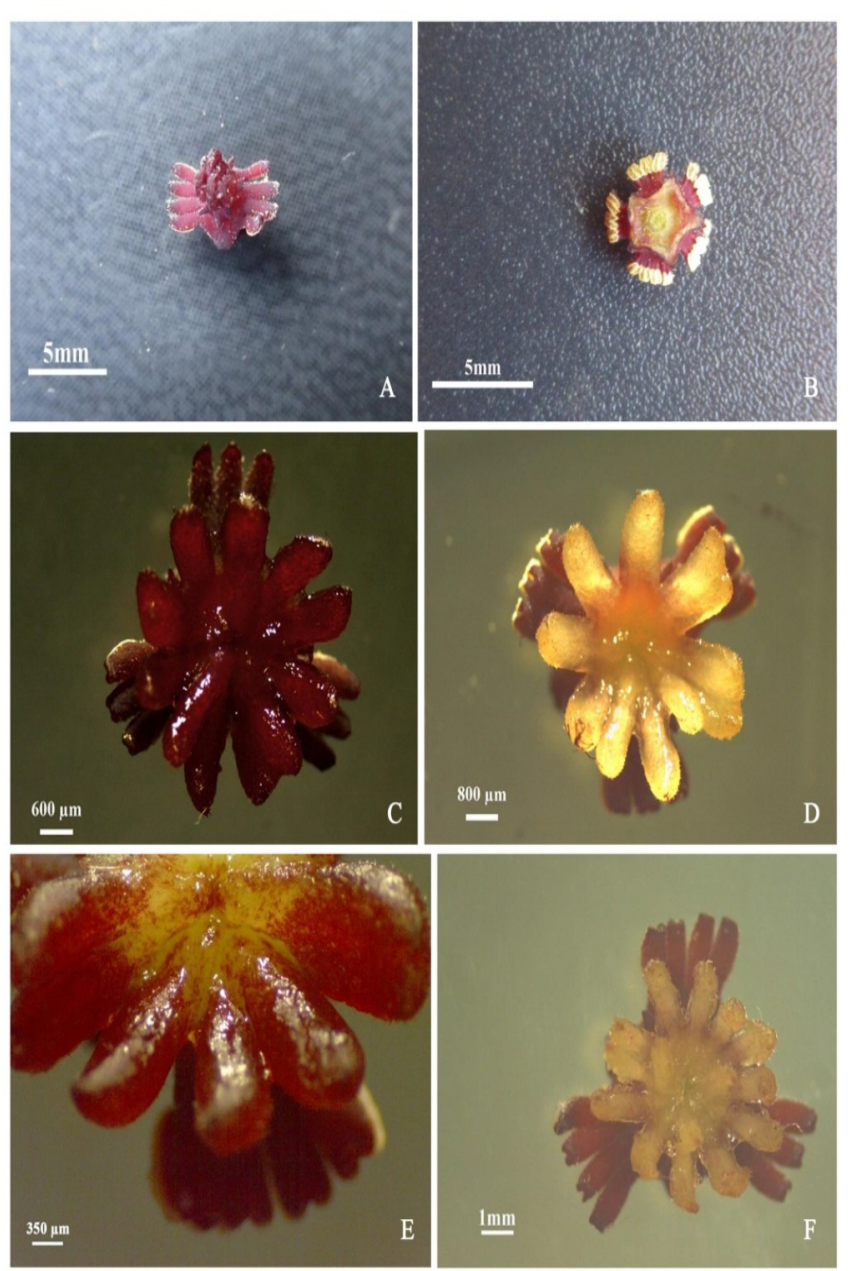

Fig. 2. Gynostemium morphology of T. duchartrei. (A) Gynostemium with 4+4 stamen pattern; (B) Gynostemium with five stamen bundles $(4+3+3+3+3)$; (C) Reddish brown gynostemium (stylar lobes open - receptive stage); (D) Pale yellow gynostemium (receptive stage); (E) Stylar lobes with reddish brown distal regions and pale yellow basal regions; (F) Gynostemium with an additional inner ring of three stylar lobes.

multicellular uncinate hairs. Alternating with the bundles of stamens, solitary pointed appendages were seen in most of the flowers, which were similar in colour to the filaments. These appendages were also seen pubescent with a large number of uncinate hairs. The gynostemium at its top radiates into a number of stylar lobes. Just below these stylar lobes, but above the whorl of stamens, there was an additional whorl of appendages (6 to 13 appendages in number). These appendages were also found pubescent with numerous uncinate hairs and were found morphologically similar in appearance to the filaments of the stamens. Repeated observation throughout the blooming period did not show any visually identifiable exudates or wetness on these appendages even at the receptive stages of the stigma.

Field observations and the subsequent microscopic analyses on the flowers of the two accessions confirmed three types of gynostemium on the basis of colour of the stylar lobes. The first type of gynostemium was the one where the entire stylar lobes were red or reddish brown (Fig. 2C); the second type with pale yellow stylar lobes (Fig. 2D) and the third type with stylar lobes having both red or reddish brown and pale yellow colours, in which the red or reddish brown colour was towards the distal region and the pale yellow colour confined to the base of the stylar lobes (Fig. 2E). In the first and third type, the intensity of the red colour on stylar lobes varied from flower to flower. However, the colour of stylar lobes remained the same within the same flower from bud stage to drooping stage and did not show any variation with respect to the time or with change in receptivity. The gynostemium on its apex was divided into a number of stylar lobes ranging from 5 to 14 and were arranged in a circular manner. Rarely, a few (13 ) of the stylar lobes were found arising at a position inner to the regular ring of stylar lobes, sometimes forming an additional ring (Fig. 2F). The stylar lobes were fleshy, wet with sticky exudates and radiating or spreading during the receptive stage (Figs. 2C \& 2D) and remained dry and closed during the non-receptive stage (Figs. 1B \& 2A). Some of the stylar lobes were bifurcated at their terminal regions. Rarely, trifurcate stylar lobes were also observed (Fig. 3A). Majority of the stylar lobes were with tapering ends. On stereomicroscopic analyses, aggregates of red spots were evident forming broad red patches on the stylar

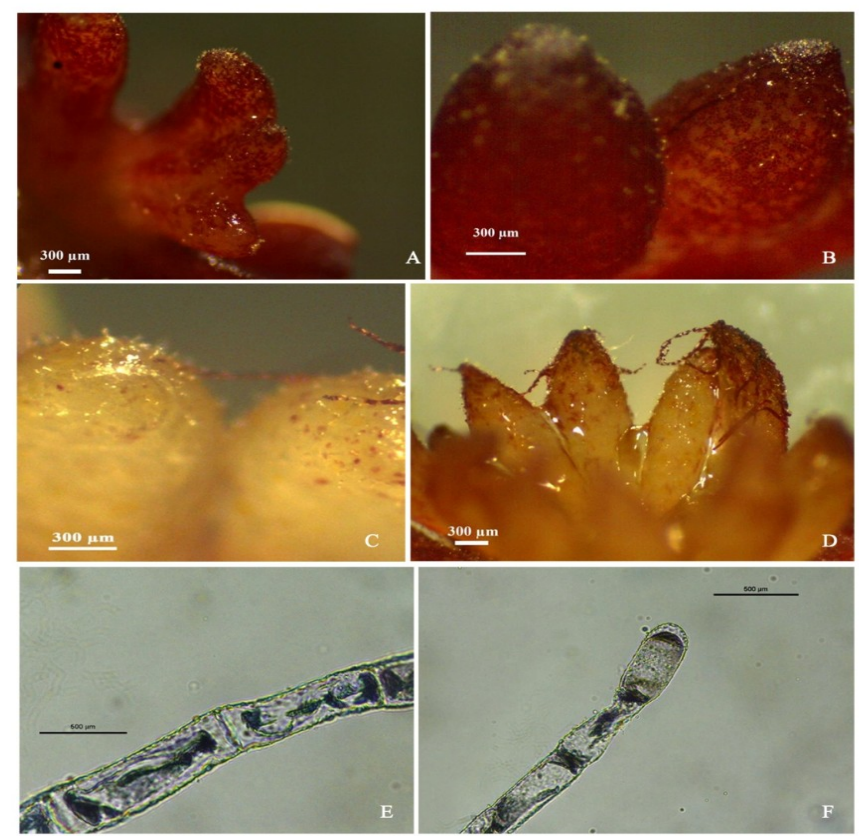

Fig. 3. Micro morphology of gynostemium in T. duchartrei. (A) Trifurcate stylar lobe; (B) Stylar lobes showing tapering ends and aggregations of smaller red spots; (C) Pale yellow stylar lobes with red patches; (D) Stylar lobes with filamentous hairs on their apex; (E) Light microscopic view of filamentous hair on gynostemium; (F) Filamentous hair on gynostemium with oval shaped terminal cell.

lobes (Fig. 3B). The number and arrangement of these patches were different from flower to flower which make them differentiated into the three types as described earlier. Thus, gynostemium with pale yellow coloured stylar lobes had the least number of red patches which were visible only when examined under stereomicroscope (Fig. 3C). Another interesting aspect was the rare occurrence of elongated, reddish brown (very rarely pale yellow) filamentous hairs with varying lengths arising from the terminal portion of stylar lobes (Fig. 3D). These hairs were uniseriate, multicellular and with elongated cells (Fig. 3E). Most of them had pointed terminal cells; some of them were with ovoid terminal cells (Fig. 3F) and still others with 
swollen sub terminal and narrower pointed terminal cells (Fig. 4A). They were morphologically similar to the hairs on the adaxial side of the tepals (Fig. 4B).

Reddish brown spots were present on the stylar column just below the base of stylar lobes, where a

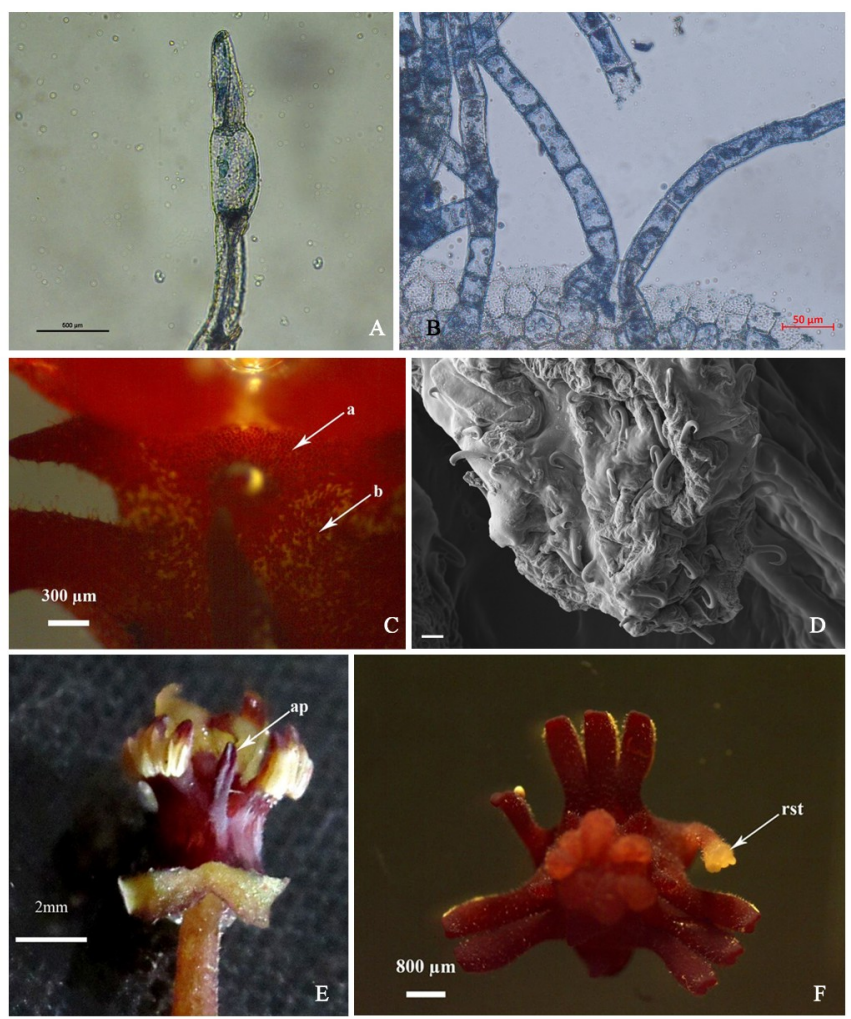

Fig. 4. Micro morphological features and variations of gynostemium in T. duchartrei. (A) Filamentous hair on gynostemium with swollen sub terminal and narrower pointed terminal cell; (B) Filamentous hairs on perianth; (C) Red spots (a) and red stripes (b) on gynostemium; (D) SEM of stylar lobe (E) Gynostemium with elongated appendage (ap) between stamen bundles; (F) Gynostemium with a rudimentary stamen (rst) in the position of appendage.

whorl of appendages was present. These appendages placed below the stylar lobes and between the bundles of stamens did not produce any visually identifiable exudates or wetness even at the time of stigma receptivity, when the stylar lobes were found wet. Below these appendages were seen some reddish stripes in yellow background (Fig. 4C). Uncinate hairs were predominantly distributed over the stylar lobes. In most of the flowers, these hairs were confined towards the terminal portion half way mark from the base of the stylar lobes. Rarely, stylar lobes with uncinate hairs all over them were also observed. The cylindrical axis of the gynostemium was also covered with uncinate hairs.

The scanning electron microscopic analysis unveiled some pieces of valuable information regarding the micro morphology of the stylar lobes. In T. duchartrei, the surface of the stylar lobe was seen irregular and rough, without any prominent stigmatic structure, protuberances or papillae anywhere. The surface of the stylar lobe was extremely folded in appearance, which resulted in depressions and furrows. The surface was also covered by a waxy substance and uncinate hairs (Fig. 4D).

\section{Variations}

Flowers of accession 2 showed variations in the morphology of the appendages alternating with the bundles of stamens. i.e., in some flowers, these appendages were longer than that of the normal ones, reaching up to the entire length of the stamen units and forming a filament, but without any anther lobes on their terminal regions (Fig. 4E). They also had a furrow on their dorsal surface, same as that present on the dorsal surface of filaments in the functional stamens. In some other flowers, these elongated appendages on their terminal region developed an amorphous yellowish structure on their tips forming a rudimentary stamen (Fig. 4F). Anthers of this rudimentary stamen contained only poorly developed sterile pollen grains. Still in some other flowers, one (Fig. 5A), two (Fig. 5B) or all the three (Fig. 5C) of these appendages had developed into complete stamens. The anthers of these stamens dehisced along with the stamens in the bundles. When tested with $1 \%$ acetocarmine, the pollen grains from these anthers showed a fertility rate of $93.5 \pm 1.05 \%$ and by FDA staining technique the pollen viability was $91.2 \pm$ $1.32 \%$.

Another interesting observation was the presence of one or two stamens, developed from the whorl of

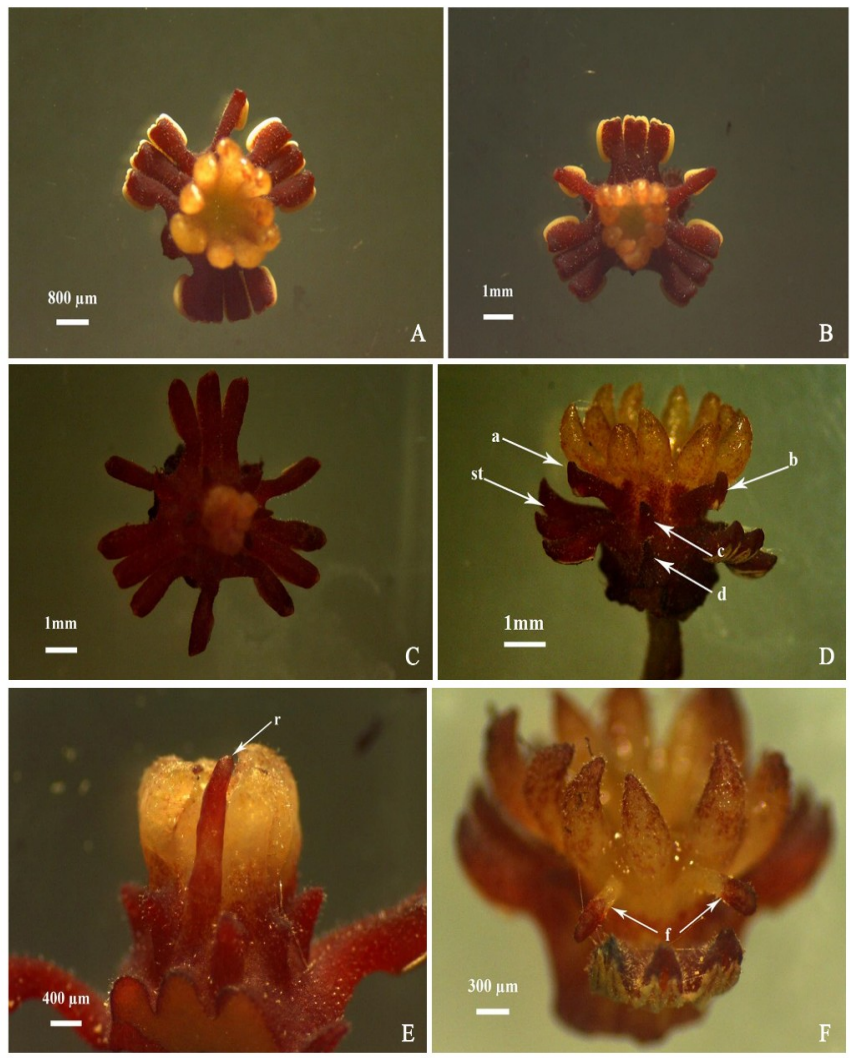

Fig. 5. Variations in gynostemium morphology of T. duchartrei. (A) Gynostemium with a single stamen in the position of appendage between two stamen bundles; (B) Gynostemium with two individual stamens, each in the position of appendage between the stamen bundles; (C) Presence of three individual stamens, each in the position of appendage between the stamen bundles; (D) Gynostemium with morphological variations: a \& b: stamens developed from the whorl of appendages below the stylar lobes st: normal stamen bundle c: appendage below the stylar lobes $\mathrm{d}$ : appendage between the stamen bundles; (E) Reddish elongated structure (r) arising among the stylar lobes; (F) Gynostemium with two finger-like structures. 
appendages just below the stylar lobes (Fig. 5D). $87.5 \pm$ $0.65 \%$ of the pollen grains collected from these stamens were found fertile when stained with $1 \%$ acetocarmine and $86 \pm 0.67 \%$ were viable when tested with FDA. The dehiscence of these anthers was also observed in parallel to that of the other functional stamens in the bundles.

Very rarely, a linear reddish appendage was seen arising along with the stylar lobes in some flowers (Fig. 5E). This structure had the same length as that of stylar lobes, but was comparatively lean with respect to the stylar lobes. This structure was wet as that of the receptive stylar lobes. These structures responded positively to the peroxidase assay for stigma receptivity. Another interesting feature noticed in the flowers of accession 2 was the presence of two small finger-like structures, each arising laterally from positions alternate to the stylar lobes (Fig. 5F). These finger-like structures had the same external morphology as that of the stylar lobes; i.e., pale yellow colour towards the base and with very small red spots on their terminal region, making that part reddish in appearance, but darker than that of the terminal regions of stylar lobes. The terminal regions of these structures were broader than that of the base and covered with uncinate hairs. These structures were wet with sticky exudates like that of the receptive stylar lobes. They also responded positively to the peroxidase assay for stigma receptivity.

\section{Reproductive Biological Studies}

\section{Fluorescein Diacetate (FDA) test for pollen viability}

The viability of fresh pollen grains was tested at different time intervals on the day of anther dehiscence and it was observed that highest pollen viability was in the pollen grains collected between 10:00 am and 12:00 pm and it was at a rate of $94.87 \pm$ $0.78 \%$ (Fig. 6A, Fig. 7). The anthers were dehisced on the second day of anthesis and thus protogynous nature of the flowers confirmed.

\section{In vitro pollen germination test}

Pollen grains were incubated in various concentrations of Brewbaker and Kwack's medium $(0.03 \%$ - 50\%). Maximum percentage of pollen germination $(66.07 \pm 1.22 \%)$ was observed in pollen grains collected between 10:00 am and 12:00 pm. Pollen germination percentage reached its peak in $T$. duchartrei when incubated in Brewbaker and Kwack's medium supplemented with 7\% Sucrose (Fig. 6B, Fig. 7). Other concentrations of Brewbaker and Kwack's medium resulted in low germination percentage.

\section{Acetocarmine staining method for pollen fertility}

The highest percentage of fertility was recorded in the pollen grains collected in between 10:00 am and 12:00 pm and it was $95.55 \pm 0.94 \%$ (Fig. 6C, Fig. 7).

\section{Peroxidase activity test for stigma receptivity}

Peroxidase activity test for stigma receptivity was conducted every hour starting from 6:00 am till 6:00 pm and the maximum receptivity was recorded between 11:00 am and 3:00 pm (Fig. 6D). The stigma was found receptive even before anthesis, and a sharp decrease in stigma receptivity was noticed after 3:00 pm.
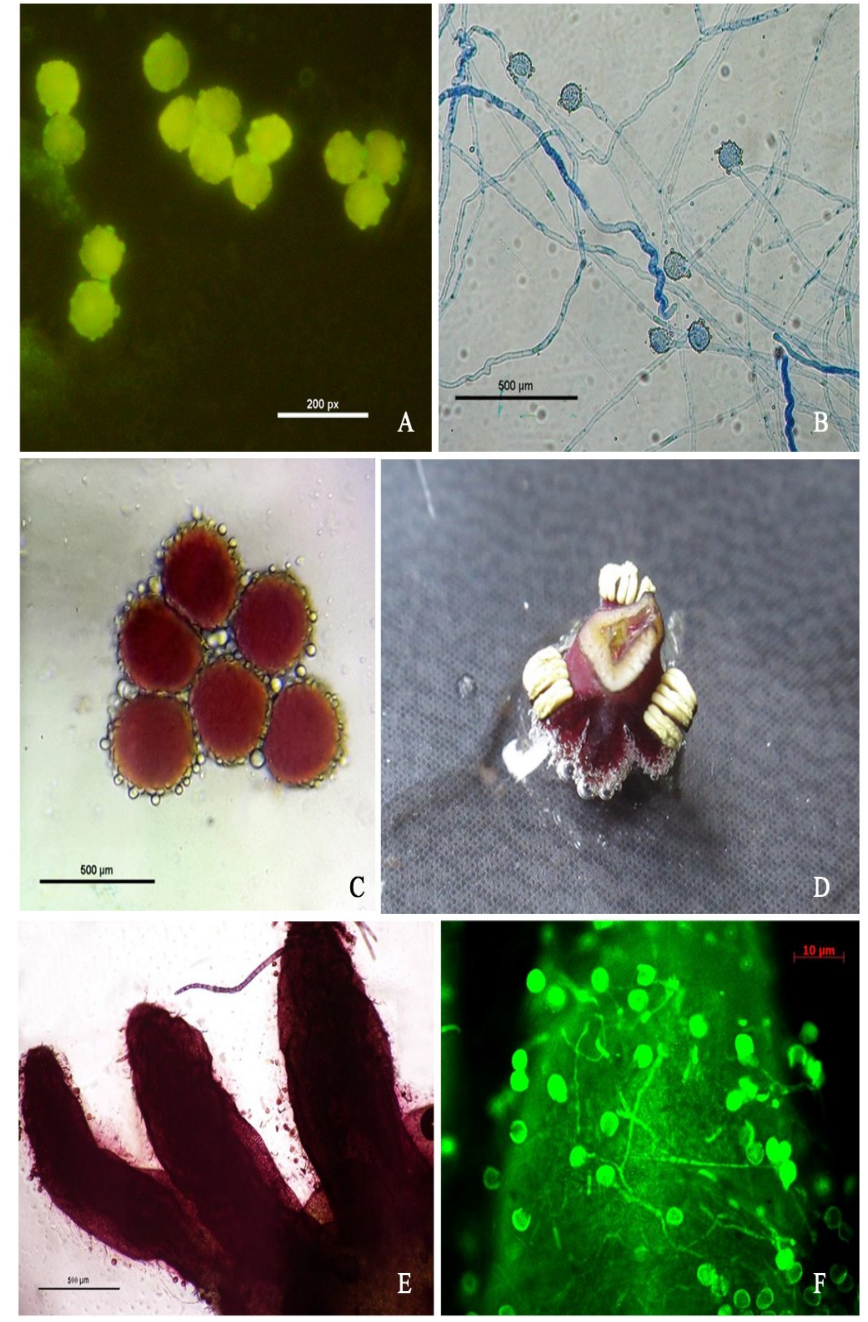

Fig. 6. Reproductive biological studies on $T$. duchartrei. (A) FDA staining-viable pollen grains showing fluorescence; (B) in vitro pollen germination; (C) Acetocarmine staining-viable pollen grains; (D) Peroxidase activity test-release of Oxygen bubbles from receptive area; (E) Cytochemical localization of stigma specific esterases indicating the receptive area in red colour; (F) Aniline blue fluorescence - germinating pollen grains on the surface of stylar lobe.

\section{Cytochemical localization of stigma-surface esterases}

The stigma specific esterases were localized on the entire stylar lobes, which imparted red colour to the receptive area during the test (Fig. 6E). Also, this red colouration was visible irrespective of the location of red patches and uncinate hairs on the stylar lobes. The filamentous hairs on the tips of stylar lobes also responded positively to the test. However, positive indication of receptivity was not seen on the appendages on the gynostemium.

\section{Aniline blue fluorescence microscopic method for stigma receptivity}

The fluorescent microscopic analyses of artificially pollinated gynostemium made it clear that the pollen grains germinated on the surface of stylar lobe, regardless of the presence or distribution of red patches and uncinate hairs (Fig. 6F). Pollen germination was not observed on the appendages and on the filamentous hairs, even though they were also pollinated with sufficient amount of viable pollen grains. 


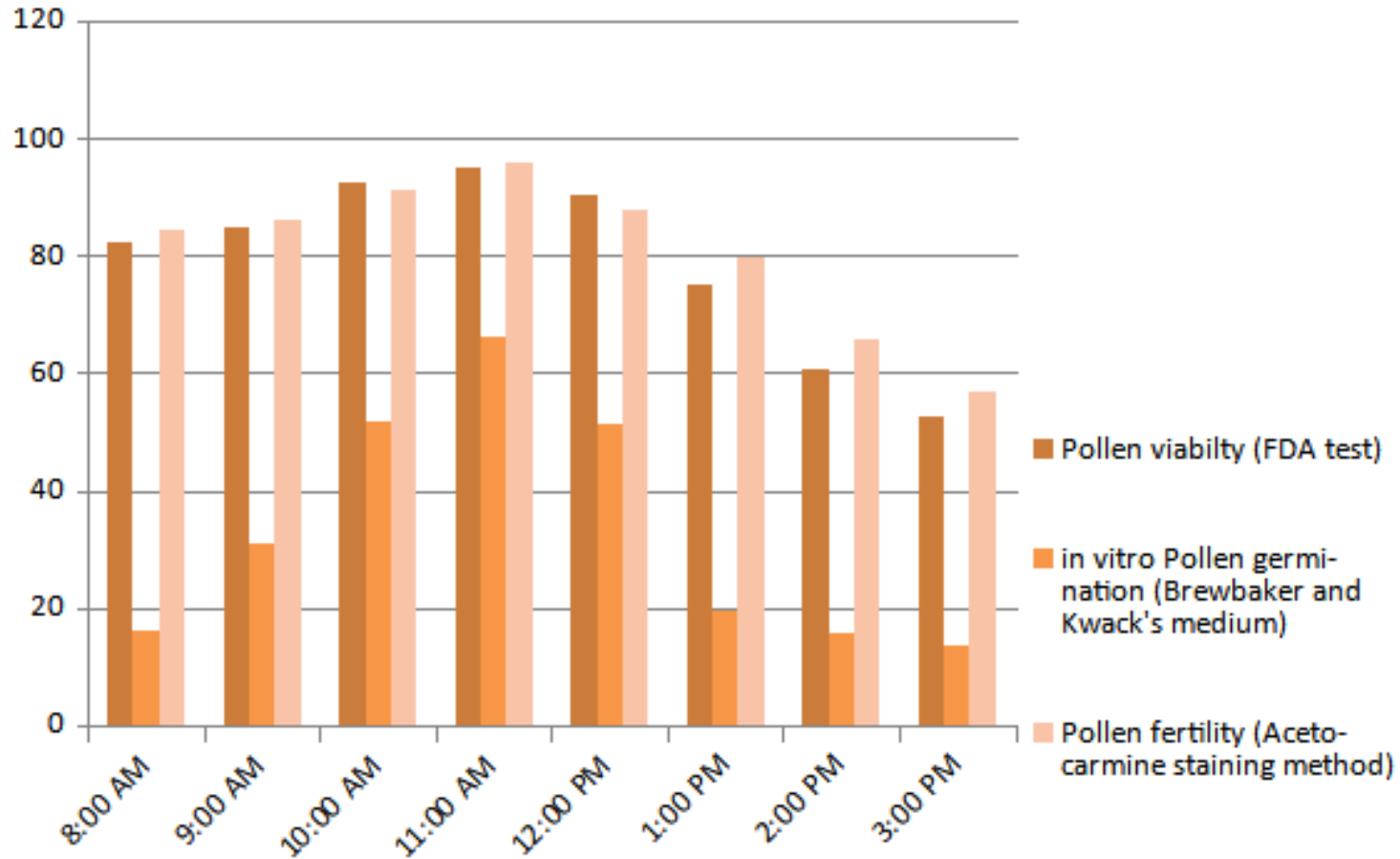

Fig. 7. Pollen viability, in vitro pollen germination and pollen fertility studies in T. duchartrei.

\section{Discussion}

Flower is the visual cue and reproductive part of angiosperms that offer a large number of key characters good for solving many of the taxonomic problems. The presence of a large number of floral forms which existed earlier during angiosperm evolution as per the fossil record shows that the floral genetic architecture provided opportunity for early, immediate and large-scale diversification in floral morphology (30). In Thottea, the levels of inter and intra-specific floral variations are very high and very sensitive from systematic point of view (7). The flowers of the genus Thottea are actinomorphic, perianth mostly broadly campanulate, urceolate, bowl or cup-shaped and trilobed with 6-36 stamens (sometimes up to 46), in 1, 2, rarely 3 or 4 series placed around the style column. The filaments are partly united to the style column forming a gynostemium (31). Reddish purple and yellowish perianth were reported earlier in T. duchartrei and T. idukkiana (7). The latter species was confirmed to be indistinguishable from $T$. duchartrei by the same authors on the basis of the detailed morphometric analyses.

There were many variations in the number of stamens as well as number and arrangement of stamen bundles in the genus Thottea. Striking fluctuations in the number of stamen and stigmatic lobes were observed earlier in T. duchartrei (32). It was also reported the occurrence of fluctuating androecial patterns in T. duchartrei, T. idukkiana, T. ponmudiana, $T$. siliquosa and T. sivarajanii (7). Both these studies reported the presence of three or more stamen bundles in T. duchartrei. But in the present study, presence of two bundles with $4+4$ stamen pattern was also observed in flowers with bilobed perianth.

The appendages alternating with the stamen bundles and those below the stylar lobes show morphological similarity to the filaments of functional stamens in bundles, in their colour and also in the presence of uncinate hairs. They do not show any visually identifiable receptivity related signals, whereas the functional stylar lobes show wetness during their receptive stage. So, these structures show more affinities to the stamens than the stylar lobes.

Bifurcate stylar lobes are a rare occurrence in the genus Thottea $(7,9,11)$ and these bifurcations in later stages of development may make the numbers fluctuating. In the present study, trifurcate stylar lobes were also noticed. Small red spots are arranged on the stylar lobes in various ways making them entirely or partially red or reddish brown or pale yellow in colour. Such red spots on stylar lobes were also reported and opined as the receptive area (33). Larger red spots and red stripes are present on the stylar column. Numerous uncinate hairs are distributed on the cylindrical part of gynostemium and on the stylar lobes entirely or towards their terminal regions and the stylar lobes become wet during the receptive stage. All these findings made us to conclude that the entire stylar lobes can be the functional stigmatic tissue in the gynostemium and the uncinate hairs specialised for pollen capture.

According to one report, staminodes are formed as a result of evolutionary reduction of stamens and they may or may not get to grips with new functions (34). Based on a study on asterids, they concluded that the entire and partial staminode whorls are generally rudimentary, transitional and without any identifiable function. Also, when the entire stamen whorl is lost, there is lesser opportunity for these non functional staminodes for their modification. In lineages with actinomorphic flowers, entire stamen whorl is replaced usually by staminodes. In the present study, striking developmental variations such as the filament alone, rudimentary stamen and normal functional stamen were found arising from the position of whorl of appendages in some flowers of accession 2. These 
developmental fluctuations indicate a transition series of reversion of stamen reduction and hence it can be confirmed that all these appendages are staminodes, formed by the reduction of an entire stamen whorl. There are many noticeable discrepancies in the number of stamen whorls in some species of Thottea such as $T$. rhizantha (stamens in 2 series), T. paucifida (2 series), T. celebica (2 series), T. anthonysamyi (2 series), T. longipedunculata (2 series), T. abrahamii (2 series), $T$. triserialis (3 series), $T$. parviflora (four series) etc. $(31,35,36)$. The occurrence of such a wide range of variation and the development of stamens from the whorl of appendages just below the stylar lobes also support the view that these appendages are formed as a result of reduction of an entire whorl of stamens just below the stylar lobes in $T$. duchartrei. Thus, the appendages beneath the stylar lobes can be considered as true staminodes (homologous to stamens) in concomitance with the earlier findings (21). It is contradictory to the report stating that there are two rows of stigmatic lobes in T. idukkiana, of which the lower one is sterile (37).

The complete sterilization of a whorl of stamens leads to the transformation of diplostemonous androecium into (ob) haplostemonous type and such a tendency of formation of complete staminodial whorls occurs also in primitive taxa having polycyclic androecium (38). The development of filaments, rudimentary stamens and one, two or three fertile stamens, each arising from the position of appendages alternate to the perianth in the present investigation indicates that these appendages are also formed as a result of reduction of stamens, which had existed earlier in this species. It indicates a kind of reverse evolution or backward evolution of staminodes to fertile stamens. Reversible staminodal evolution was reported in Mentzelia section Bartonia of family Losaceae (39). In a number of species of the family Xyridaceae, the entire stamen whorl is either absent or modified to staminodes (40). However, when considering the staminodes in a general account, in some plants, the staminodes acquire various functions such as nutrition, prevention of self pollination, pollinator attraction etc. (38). In the genus Aquilegia, they are meant to protect the carpel from pathogen or herbivore attack in the early stages of development (41) and in Phanera yunnanensis (Caesalpinioideae), the staminodes control the pollen deposition and removal rates (42). However, such functions of staminodes were not determined in the present study. Thottea has another evolutionary significance with regard to the evolution of growth form and woodiness character in Piperales, since it forms a connecting link between the herbaceous and woody forms of Asaroideae and Aristolochioideae (43).

The reddish, elongated and narrow structure seen along with the stylar lobes are morphologically similar to the stylar lobes even though there is some variation in colour and diameter. The small finger-like structures arising laterally alternate to the stylar lobes are also miniature forms of stylar lobes. Also, both of these structures responded positively to the peroxidase activity test for stigma receptivity. High levels of peroxidase activity are exhibited by mature stigmas during their peak receptivity period (44). Thus, it is obvious that the stylar lobes of Thottea duchartrei show some architectural variations in their morphology.

There are reports on the types of trichomes on leaves and floral parts of different Thottea species and reported five kinds of hairs such as uncinate hairs, filiform long terminal celled hairs, swollen terminal celled hairs, pyramidal shaped hairs and multicellular cylindrical falcate hairs (45). The comparative microscopic analysis of both the elongated hairs on the gynostemium and the hairs on the adaxial surface of the perianth conveyed that these are the same kind of hairs and that they show morphological similarity with the multicellular cylindrical falcate hairs in Thottea (45).

Stigma is the receptive part of the pistil, which helps in pollen binding and pollen tube growth. They are generally grouped into wet stigmas having surface cells which lyse to discharge a viscous fluid on the stigmatic surface and dry stigmas which are with unscathed surface cells which form papillae (46). The scanning electron micrographs of the stylar lobes of $T$. duchartrei did not reveal any evident stigmatic structures or papillae, other than ridges, waxy coating and uncinate hairs. Thus, a specific stigmatic structure could not be determined as per the morphological analysis of the gynostemium.

Pollen viability and stigma receptivity are two main factors which are crucial in determining the efficiency of reproductive organs to carry out successful pollination which then leads to fertilization and zygote formation (47). The duration and peak period of stigma receptivity as evidenced by peroxidase test, esterase test and in vivo pollen germination is crucial in determining the reproductive success of a plant species (48). Thottea duchartrei shows a high level of pollen viability and in vitro pollen germination when compared to that of $T$. barberi which was observed to be $18 \%$ and $8 \%$ respectively when tested in an earlier study (49). Pollen viability was reported significantly high in eight species of Thottea (14). The present study reveals very high pollen fertility in T. duchartrei.

The stylar lobes are receptive even before anthesis and the plant shows protogyny. Cytochemical localization of stigma surface esterases and aniline blue fluorescence microscopic method for in vivo pollen germination clearly depicted the exact receptive area on the gynostemium. Even though an earlier study could not recognize any specific stigmatic protuberance on the stylar lobes and considered it as a structure only for capturing pollen grains and as not a part of gynoecium (22), the present study shows that the stigmatic tissues are present on the entire stylar lobes and the entire stylar lobe is receptive and supports pollen germination irrespective of the distribution of red spots and uncinate hairs on it (22). Hence, the stylar lobes can be considered as stigmatic lobes. The appendages just below the stylar lobes and those between the stamen bundles did not show any kind of receptivity and pollen germination. Thus, reproductive biological studies are pointing out the staminodial nature of the appendages. Even though the unique filamentous hairs on the tip of stylar lobes manifested esterase 
activity, pollen tube growth through these hairs was not observed. But, in a study, conducted in Trithuria (Hydatellaceae), pollen tube growth was observed within the cell walls of unbranched multicellular hairs on stigma (50). However, the filamentous hairs on the gynostemium of $T$. duchartrei are not involved in any kind of reproductive function.

\section{Conclusion}

Morphological study on the flowers of $T$. duchartrei Sivar., A.Babu and Balach. revealed the prevalence of complex structural variations in the gynostemium and associated structures. The gynostemium has variations in colour, form and number of stylar lobes and the number and arrangements of stamens. Micro morphological analysis of the appendages has evidently portrayed the different evolutionary stages of their formation by stamen reduction. Studies on reproductive biology supplemented the finding that these appendages do not form any part of gynoecium since they do not possess any stigmatic tissue. The stigmatic tissues were localized on the entire stylar lobes and hence they can be considered as the true stigmatic tissue. In this context, it was able to uncover the morphological and functional parameters of gynostemium in T. duchartrei. Further studies shall be conducted in order to explore the morphological characters and functional parameters of this structure in other species of Thottea.

\section{Acknowledgements}

We express our gratitude to University Grants Commission, Bahadurshah Zafar Marg, New Delhi for extending financial support in the under the JRF scheme to the first author. We are obliged to the University of Kerala for approving the research proposal. We sincerely acknowledge the Kerala Forest Department for providing the necessary sanction to explore different areas of the Western Ghats with respect to this research. We wish to put on record our special thanks to the Central Laboratory for Instrumentation and Facilitation (CLIF), University of Kerala, Kariavattom, Thiruvananthapuram and Jawaharlal Nehru Tropical Botanic Garden and Research Institute, Palode, Thiruvananthapuram for providing instrumental support for the study.

\section{Authors' contributions}

SPN, SAK and SKS conceived the idea and planned the experiments. SPN and SKS collected the plant samples. SKS performed the experiments under the supervision of SPN and SAK. All authors analyzed the research data and drafted the manuscript.

\section{Compliance with ethical standards}

Conflict of interest: The authors do not have any conflict of interests to declare.

Ethical issues: None.

\section{References}

1. Endress PK. Development and evolution of extreme synorganization in angiosperm flowers and diversity: a comparison of Apocynaceae and Orchidaceae. Ann Bot (Oxford). 2016;117(5):749-67. https://doi.org/10.1093/aob/mcv119

2. Gonzalez F, Stevenson DW. Gynostemium development in Aristolochia (Aristolochiaceae). Bot Jahrb Syst. 2000;122(2):249-91.

3. Gonzalez F, Stevenson DW. Perianth development and systematics of Aristolochia. Flora. 2000;195(4):370-91. https://doi.org/10.1016/ S0367-2530(17)30995-7

4. Rudall PJ, Bateman RM. Roles of synorganisation, zygomorphy and heterotopy in floral evolution: the gynostemium and labellum of orchids and other lilioid monocots. Biol Rev Cambridge Philos Soc. 2002;77(3):403-41. https://doi.org/10.1017/S1464793102005936

5. Wagstaff SJ, Wege J. Patterns of diversification in New Zealand Stylidiaceae. Amer J Bot. 2002;89(5):865-74. https://doi.org/10.3732/ ajb.89.5.865

6. Yao TL. Aristolochiaceae. In: Kiew R, Chung RCK, Saw LG, Soepadmo E, (eds). Flora of Peninsular Malaysia, Series II: seed plants, vol 5. Kepong: Forest Research Institute Malaysia; 2015. p. 546.

7. Shaiju PN, Omanakumari N. Floral morphology and systematics of the genus Thottea Rottb. (Aristolochiaceae) from Western Ghats, India. Pl Syst Evol. 2010;288:213-25. https://doi.org/10.1007/s00606010-0326-X

8. Murugan C. A review of the genus Thottea (Aristolochiaceae) from the Andaman and Nicobar Islands, including a new record for India. Rheedea. 2011;2:149-52.

9. Sunil CN, Kumar VVN. Thottea adichilthottiana (Aristolochiaceae), a new species from Ernakulam, Western Ghats, India. Webbia. 2014;69(2):239-42. https://doi.org/10.1080/00837792.2014.951205

10. Robi AJ, Jose PA, Udayan PS. Thottea sasidharaniana sp. nov. (Aristolochiaceae) from Peninsular India. Nordic Journal of Botany. 2014 Feb;32(1):11-14. https://doi.org/10.1111/j.1756-1051.2013.01577.x

11. Kumar ESS, Mathew SP, Jabbar MA, Krishnan SG, Murugesan, K. Rediscovery of Thottea dalzellii (Hook.f.) Karthik and Moorthy (Aristolochiaceae) from the Western Ghats. Int J Advanced Res. 2015;3(4):1-4.

12. Shaiju PN, Omanakumari N. Inflorescence morphology and systematics of the genus Thottea Rottb. (Aristolochiaceae) from the Western Ghats, India. Systematics and Biodiversity. 2009;7(4):445-51. https://doi.org/10.1017/S1477200009990181

13. Shaiju PN. Pollen morphology of the genus Thottea. Phytomorphology: An International Journal of Plant Morphology. 2012;62(3):12535 .

14. Shaiju PN, Omanakumari N. Chromosomal evolution in the genus Thottea Rottb. (Aristolochiaceae) from the Western Ghats, India. Nucleus. 2013;56(3):179-82. https://doi.org/10.1007/s13237-013-00953

15. Yigit N. Micromorphological Studies on Plants and Their Importance. In: Efe R, Matchavariani L, Yaldir A, Levai L. (eds). Developments in Science and Engineering. 2016. p.113-24.

16. Silva ALE, de Lima Terceiro LE, de Lima MF, Costa-Silva R, Dos Santos EAV, Agra MF. Leaf and stem micromorphology of Byrsonima sericea DC. by light and scanning electron microscopy. Microscopy Research and Technique. 2020;83(3):287-96. https://doi.org/10.1002/ jemt.23412

17. Song JH, Yang S, Choi G. Taxonomic implications of leaf micromorphology using microscopic analysis: A tool for identification and authentication of Korean Piperales. Plants. 2020;9(5):566. https://doi.org/10.3390/plants9050566

18. Konarska A. Comparative micromorphology and anatomy of flowers and floral secretory structures in two Viburnum species. Protoplasma. 2017;254(1):523-37.https://doi.org/10.1007/s00709-016-09720

19. Giuliani CL, Foggi BR, Lippi MM. Floral morphology, micromorphology and palinology of selected Sedum s.l. species (Crassulaceae). Plant Biosystems - An International Journal Dealing with all Aspects of Plant Biology. 2018;152(3):1-16. https://doi.org/ 10.1080/11263504.2016.1271056 
20. Lubna, Zafar M, Ahmad M, Shaheen S, Sultana S, Rehman SU, et al. Micromorphological investigation of leaf epidermis and seeds of Vitaceae from Pakistan using light microscopy and scanning electron microscopy. Microscopy Research and Technique. 2019;82(4):33544.https://doi.org/10.1002/jemt.23102

21. Renuka C, Swarupanandan K. Morphology of the flower in Thottea siliquosa and the existence of staminodes in Aristolochiaceae. Blumea. 1986;31(2):313-18.

22. Leins P, Erbar C, Van Heel WA. Note on the floral development of Thottea (Aristolochiaceae). Blumea. 1988;33(2):357-70.

23. Heslop-Harrison J, Heslop-Harrison Y. Evaluation of pollen viability by enzymatically induced fluorescence; intracellular hydrolysis of fluorescein diacetate. Stain Technol. 1970;45(3):115-20. https:// doi.org/10.3109/10520297009085351

24. Brewbaker JL, Kwack BH. The essential role of calcium ion in pollen germination and pollen tube growth. Amer J Bot. 1963;50(9):859-65. https://doi.org/10.1002/j.1537-2197.1963.tb06564.x

25. Shivanna KR, Tandon R. Reproductive Ecology of Flowering Plants: A Manual. New Delhi: Springer; 2014.p.42. https://doi.org/ 10.1007/978-81-322-2003-9

26. Kearns CA, Inouye DW. Techniques for the Pollination Biologists. Niwot: University press of Colorado; 1993.

27. Mattsson O, Knox RB, Heslop-Harrison J, Heslop-Harrison Y. Protein pellicle of stigmatic papillae as a probable recognition site in incompatibility reactions. Nature. 1974;247:298-300. https://doi.org/ $10.1038 / 247298 \mathrm{a} 0$

28. Sharma MV, Kuriakose G, Shivanna KR. Reproductive strategies of Strobilanthes kunthianus, an endemic, semelparous species in southern Western Ghats, India Bot J Linn Soc. 2008;157(1):155-63. https://doi.org/10.1111/j.1095-8339.2008.00786.x

29. Shivanna KR, Rangaswamy NS. Pollen Biology: a laboratory manual. Berlin: Springer; 1992. https://doi.org/10.1007/978-3-642-77306-8

30. Soltis PS, Brockington SF, Yoo MJ, Piedrahita A, Latvis M, Moore MJ, et al. Floral variation and floral genetics in basal angiosperms. Amer J Bot. 2009;96(1):110-28. https://doi.org/10.3732/ajb.0800182

31. Hou D. Florae Malesianae Praecursores LXII On the genus Thottea (Aristolochiaceae). Blumea. 1981;27(2):301-32.

32. Nazarudeen A, Sabu T. Staminal instability in Thottea duchartrei. Indian J Forest. 2002;25(2):194-95.

33. Shaiju PN. Systematics of the genus Thottea Rottb. (Aristolochiaceae) from the Western Ghats [Thesis], Kariavattom: University of Kerala; 2009.

34. Walker-Larsen J, Harder LD. The evolution of staminodes in angiosperms: patterns of stamen reduction, loss, and functional re-in$\begin{array}{llll}\text { vention. Amer J B } & \text { Bot. }\end{array}$ https://doi.org/10.2307/2656866

35. Dan M, Mathew PJ, Unnithan CM, Pushpangadan P. Thottea abrahamii a new species of Aristolochiaceae from Peninsular India. Kew Bull. 1996;51(1):179-82. https://doi.org/10.2307/4118756

36. Yao TL. Nine new species of Thottea (Aristolochiaceae) in Peninsular Malaysia and Singapore, with two taxa in Peninsular Malaysia redefined and a taxon lectotypified. Blumea. 2013;58(3):245-62. https://doi.org/10.3767/000651913X675791

37. Pandurangan AG, Nair VJ. Thottea idukkiana - a new species of Aris tolochiaceae from Kerala, India. J Econ Taxon Bot. 1993;17(2):46567.

38. Decraene LPR, Smets EF. Staminodes: their morphological and evolutionary significance. Bot Rev. 2001;67(3):351-402. https://doi.org/ 10.1007/BF02858099

39. Botnaru L, Schenk JJ. Staminode evolution in Mentzelia section Bartonia (Loasaceae) and its impact on insect visitation rates. Bot J Linn Soc. 2019;190:151-64. https://doi.org/10.1093/botlinnean/boz012
40. Sajo MG, Oriani A, Scatena VL, Rudall PJ. Floral ontogeny and vasculature in Xyridaceae, with particular reference to staminodes and stylar appendages. Pl Syst Evol. 2017;303:1293-310. https://doi.org/ 10.1007/s00606-017-1438-3

41. Meaders C, Min Y, Freedberg KJ, Kramer E. Developmental and molecular characterization of novel staminodes in Aquilegia. Ann Bot (Oxford). 2020;126(2):231-43. https://doi.org/10.1093/aob/ mcaa029

42. Wang M, Huang S, Li M, McKey D, Zhang L. Staminodes influence pollen removal and deposition rates in nectar-rewarding self-incompatible Phanera yunnanensis (Caesalpinioideae). J Trop Ecol. 2019;35(1):34-42. https://doi.org/10.1017/S0266467418000433

43. Oelschlägel B, Wagner S, Salomo K, Pradeeep NS, Yao TL, Isnard S et al. Implications from molecular phylogenetic data for systematics, biogeography and growth form evolution of Thottea (Aristolochiaceae). Gard Bull Singapore. 2011;63(1\&2):259-75.

44. McInnis SM, Emery DC, Porter R, Desikan R, Hancock JT, Hiscock SJ. The role of stigma peroxidases in flowering plants: insights from further characterization of a stigma-specific peroxidase (SSP) from Senecio squalidus (Asteraceae). J Exp Bot. 2006;57(8):1835-46. https://doi.org/10.1093/jxb/erj182

45. Kumar ESS, Chitra CR, Khan AES. Studies on the Trichomes of Indian Thottea Rottb. (Aristolochiaceae). J Econ Taxon Bot Addit Ser. 2001;19:237-40

46. Edlund AF, Swanson R, Preuss D. Pollen and stigma structure and function: the role of diversity in pollination. The Plant Cell. 2004;16(1):S84-S97. https://doi.org/10.1105/tpc.015800

47. Zulkarnain Z, Eliyanti E, Swari EI. Pollen viability and stigma receptivity in Swainsona formosa (G. Don) J. Thompson (Fabaceae), an ornamental legume native to Australia. Ornam. Hortic. 2019;25(2):158-67. https://doi.org/10.14295/oh.v25i2.2011

48. Biswas P, Mohammad J. Studies on esterase and peroxidase activity of Clerodendrum inerme (Linn.) Gaertn. in relation to stigma receptivity. Int J Adv Res Biol Sci. 2016;6(3):386-89.

49. Femy KH, Radhamany PM, Gangaprasad A. Reproductive biology of Thottea barberi (Gamble) Ding Hou. (Aristolochiaceae) - an endemic taxon of southern Western Ghats, Kerala, India. Int J Plant Rep Biol. 2014;6(1):99-104.

50. Prychid CJ, Sokoloff DD, Remizowa MV, Tuckett RE, Yadav SR, Rudall PJ. Unique stigmatic hairs and pollen-tube growth within the stigmatic cell wall in the early-divergent angiosperm family $\mathrm{Hy}$ datellaceae. Ann Bot. (Oxford). 2011;108(4):599-608. https://doi.org/ 10.1093/aob/mcr021

\section{Additional information}

Peer review information: Plant Science Today thanks Sectional Editor and the other anonymous reviewers for their contribution to the peer review of this work.

Reprints and permissions information is available at https://horizonepublishing. com/journals/index.php/PST/open_access_policy

Publisher's Note: Horizon e-Publishing Group remains neutral with regard to jurisdictional claims in published maps and institutional affiliations.

To cite this article: Sayoojia K S, Sreekala A K, Shaiju P N. Gynostemium morphology and floral biology of Thottea duchartrei Sivar., A.Babu \& Balach. (Aristolochiaceae), an endemic species from Western Ghats, India. Plant Science Today. 2021;8(4):924-932. https://doi.org/10.14719/pst.2021.8.4.1315

Plant Science Today, published by Horizon e-Publishing Group, is covered by Scopus, Web of Science, BIOSIS Previews, Clarivate Analytics, etc. See https://horizonepublishing.com/journals/index.php/PST/indexing_abstracting 